\title{
Effect of supplementation of fermented milk drink containing probiotic Lactobacillus casei Shirota on the concentrations of aflatoxin biomarkers among employees of Universiti Putra Malaysia: a randomised, double-blind, cross-over, placebo-controlled study
}

\author{
Sabran Mohd Redzwan ${ }^{1}$, Mohd Sokhini Abd Mutalib ${ }^{1}$, Jia-Sheng Wang ${ }^{2}$, Zuraini Ahmad ${ }^{3}$, Min-Su Kang ${ }^{2}$, \\ Nurul 'Aqilah Abdul Rahman ${ }^{1} \dagger$, Elham Nikbakht Nasrabadi ${ }^{\dagger}$ and Rosita Jamaluddin ${ }^{1 *}$ \\ ${ }^{1}$ Department of Nutrition and Dietetics, Faculty of Medicine and Health Sciences, Universiti Putra Malaysia, 43400 Serdang, \\ Selangor, Malaysia \\ ${ }^{2}$ Department of Environmental Health Science, College of Public Health, The University of Georgia, Athens, GA 30602, USA \\ ${ }^{3}$ Department of Biomedical Sciences, Faculty of Medicine and Health Sciences, Universiti Putra Malaysia, 43400 Serdang, \\ Selangor, Malaysia \\ (Submitted 31 March 2015 - Final revision received 3 September 2015 - Accepted 17 September 2015-First published online 22 October 2015)
}

\section{Abstract}

Human exposure to aflatoxin is through the diet, and probiotics are able to bind aflatoxin and prevent its absorption in the small intestine. This study aimed to determine the effectiveness of a fermented milk drink containing Lactobacillus casei Shirota (LcS) (probiotic drink) to prevent aflatoxin absorption and reduce serum aflatoxin $\mathrm{B}_{1}$-lysine adduct $\left(\mathrm{AFB}_{1}\right.$-lys) and urinary aflatoxin $\mathrm{M}_{1}$ concentrations. The present study was a randomised, double-blind, cross-over, placebo-controlled study with two 4-week intervention phases. In all, seventy-one subjects recruited from the screening stage were divided into two groups - the Yellow group and the Blue group. In the 1st phase, one group received probiotic drinks twice a day and the other group received placebo drinks. Blood and urine samples were collected at baseline, 2nd and 4th week of the intervention. After a 2-week wash-out period, the treatments were switched between the groups, and blood and urine samples were collected at the 6th, 8th and 10th week (2nd phase) of the intervention. No significant differences in aflatoxin biomarker concentrations were observed during the intervention. A within-group analysis was further carried out. Aflatoxin biomarker concentrations were not significantly different in the Yellow group. Nevertheless, ANOVA for repeated measurements indicated that $\mathrm{AFB}_{1}$-lys concentrations were significantly different $(P=0.035)$ with the probiotic intervention in the Blue group. The 2 nd week $\mathrm{AFB}_{1}$-lys concentrations $(5 \cdot 14$ (sD $2 \cdot 15) \mathrm{pg} / \mathrm{mg}$ albumin (ALB)) were significantly reduced $(P=0.048)$ compared with the baseline $(6 \cdot 24$ (sD 3.42$) \mathrm{pg} / \mathrm{mg} \mathrm{ALB})$. Besides, the 4 th week $\mathrm{AFB}_{1}$-lys concentrations were significantly lower $(P<0.05)$ with probiotic supplementation than with the placebo. Based on these findings, a longer intervention study is warranted to investigate the effects of continuous LcS consumption to prevent dietary aflatoxin exposure.

Key words: Probiotic bacteria: Lactobacillus casei Shirota: Aflatoxin biomarkers: Serum aflatoxin $\mathbf{B}_{1}$-lysine adduct: Urinary aflatoxin $\mathbf{M}_{1}$

Aflatoxin is a fungal toxin produced by Aspergillus flavus and Aspergillus paraciticus ${ }^{(1)}$, found in many food items such as nuts, cereals, and spices and herbs ${ }^{(2)}$. Chronic aflatoxin exposure is linked to the development of hepatocellular carcinoma $(\mathrm{HCC})^{(3)}$. Global statistics indicate that more than fifty-five billion people suffer from uncontrolled exposure to aflatoxins ${ }^{(4)}$. Moreover, unawareness of the public about aflatoxincontaminated foods has been reported by some studies ${ }^{(5-8)}$.
The occurrence of aflatoxin in foodstuffs is prevalent in many developing countries in Africa and Asia. Aflatoxicosis is prevalent at an alarming rate in these countries and many cases have been reported and have caused deaths ${ }^{(9-11)}$. In Malaysia, the consumption of aflatoxin-contaminated noodles caused acute hepatic encephalopathy in thirteen children, as up to $3 \mathrm{mg}$ of aflatoxin was suspected to be present in a single serving of the contaminated noodles ${ }^{(9)}$.

\footnotetext{
Abbreviations: $\mathrm{AFB}_{1}$, aflatoxin $\mathrm{B}_{1} ; \mathrm{AFB}_{1}$-lys, aflatoxin $\mathrm{B}_{1}$-lysine adduct; $\mathrm{AFM}_{1}$, aflatoxin $\mathrm{M}_{1}$; $\mathrm{ALB}$, albumin; LcS, Lactobacillus casei Shirota.

* Corresponding author: Dr R. Jamaluddin, fax +603 8942 6769, email rositaj@upm.edu.my

$\dagger$ Present address: Department of Social and Preventive Medicine, Julius Centre University of Malaya, Faculty of Medicine, University of Malaya, 50603 Kuala Lumpur, Malaysia.

\$ Present address: Griffith Health Institute, Griffith University, Gold Coast, QLD, Australia.
} 
Although strict food regulations imposed by many countries were successful in eliminating or limiting the exposure, it is believed that some aflatoxin-contaminated foods still persist in the human food resources ${ }^{(1)}$ and aflatoxin-contaminated foods cannot be neglected. Therefore, secondary prevention steps such as dietary or clinical interventions are developed as they are able to reduce aflatoxin bioavailability in the body or ameliorate aflatoxin-induced damage ${ }^{(12)}$. Despite the effectiveness of the non-nutritional adsorbents such as clay and activated $\mathrm{C}$ to bind aflatoxin and prevent aflatoxin absorption, there should also be other more practical alternatives.

The concept of probiotic-mediated detoxification has been proposed and supported by several findings from in vitro and in vivo animal studies ${ }^{(13-16)}$ as one of the dietary approaches to prevent human exposure to aflatoxin. Although the mechanism by which probiotic bacteria bind to aflatoxin is unclear, it is suggested that the bacteria adsorb aflatoxins to the surface of the bacterial cell wall through a weak binding associated with hydrophobic interactions between the peptidoglycan layers ${ }^{(14)}$ and consequently limit the intestinal uptake. Lactobacillus casei Shirota (LcS) is one of the potential probiotics capable of doing so. Findings from in vitro studies ${ }^{(13,15)}$ using this bacterium led us to conduct an experiment on a murine model, where LcS significantly reduced aflatoxin blood serum levels in aflatoxininduced rats ${ }^{(16)}$. The outcomes of the animal study were valuable $^{(16)}$, but the application and effectiveness of LcS in humans are not yet completely understood. Nevertheless, a couple of clinical studies showed that using a mixture of probiotics effectively reduced the biomarkers of aflatoxin ${ }^{(17,18)}$, and these findings show that probiotic bacteria have the potential to act as adsorbents of aflatoxins in humans.

In the present study, two biomarkers of aflatoxin $\mathrm{B}_{1}\left(\mathrm{AFB}_{1}\right)_{-}$ namely, serum aflatoxin $\mathrm{B}_{1}$-lysine adduct $\left(\mathrm{AFB}_{1}\right.$-lys) and urinary aflatoxin $\mathrm{M}_{1}\left(\mathrm{AFM}_{1}\right)$ - were investigated. These aflatoxin-specific biomarkers are used in many epidemiological studies $^{(19-22)}$ and are reliable molecular biomarkers for the study of human exposure to aflatoxin $^{(11)}$ as well as the surrogate efficacy biomarkers of aflatoxin for the assessment of different therapeutic/intervention agents and techniques in human intervention trials ${ }^{(23-25)}$. When humans are exposed to $\mathrm{AFB}_{1}$ through the diet ${ }^{(1)}$, the toxin is absorbed via a passive diffusion $^{(26)}$ in the intestinal tract, primarily in the duodenum. A study involving human volunteers found that $\mathrm{AFB}_{1}$ equivalents' absorption into systemic circulation was rapid with peak concentrations achieved within approximately $1 \mathrm{~h}^{(27)}$, in agreement with data found in rats, where $\mathrm{AFB}_{1}$ was absorbed quickly in the small intestine ${ }^{(28)}$. Once absorbed, $\mathrm{AFB}_{1}$ is distributed via blood ${ }^{(29,30)}$. In rats, $\mathrm{AFB}_{1}$ is concentrated in the liver 30 min after an intraperitoneal dosage, but it can take up to $24 \mathrm{~h}$ with an oral dose ${ }^{(31)}$. In the liver, $\mathrm{AFB}_{1}$ is metabolised by CYP450 enzymes, where the metabolites can be excreted or interact with other biological molecules such as DNA and proteins ${ }^{(32-34)}$. $\mathrm{AFB}_{1}$-lys adduct is formed when $\mathrm{AFB}_{1}$ is metabolised into a reactive epoxide $\left(\mathrm{AFB}_{1}-8,9\right.$-epoxide), where it can further react with serum albumin (ALB) to form a long-lived lysine adduct ${ }^{(11)}$. Regarding $\mathrm{AFM}_{1}$ formation, $\mathrm{AFB}_{1}$ undergoes hydrolysis where the metabolite is excreted via urine ${ }^{(33)}$. It is found that $1 \cdot 2-2 \cdot 2 \%$ of ingested $\mathrm{AFB}_{1}$ is converted into $\mathrm{AFM}_{1}$ and excreted via urine in humans ${ }^{(35)}$, whereas the conversion rate varies between animals depending on their ability to metabolise $\mathrm{AFB}_{1}^{(36)}$.

Each biomarker has a characteristic half-life within the body ${ }^{(37)}$. The detection of urinary $\mathrm{AFM}_{1}$ reflects short-term exposure, probably $1-3 \mathrm{~d}^{(11)}$ and varies day to day depending on the amount of ingested aflatoxin-contaminated foods ${ }^{(37)}$. Conversely, $\mathrm{AFB}_{1}$-lys has a half-life in the body of $30-60 \mathrm{~d}^{(37)}$ and its detection integrates exposure over a longer period $^{(11,37,38)}$. Indeed, these two biomarkers serve as elegant tools to provide very useful information on the extent of human exposure to aflatoxin. Of great significance is a positive correlation between serum $\mathrm{AFB}_{1}$-lys and urinary $\mathrm{AFB}_{1}$-DNA adduct, a pro-mutagenic DNA lesion of aflatoxin exposure ${ }^{(11,39)}$, which is linked to the development of $\mathrm{HCC}^{(3,11)}$

In the present study, we hypothesised that probiotic bacteria can provide a barrier that can limit aflatoxin absorption by binding to aflatoxin, where an aflatoxin-bacteria complex is formed and excreted eventually via the faeces. Therefore, the objective of this study was to determine whether the supplementation of fermented milk drink containing probiotic LCS could prevent aflatoxin absorption and subsequently reduce the circular production of serum $\mathrm{AFB}_{1}$-lys and urinary $\mathrm{AFM}_{1}$.

\section{Methods}

\section{Study design}

Ethics approval for this study was obtained from the Ethics Committee for Research Involving Human Subjects Universiti Putra Malaysia (UPM), Malaysia, and all the procedures were carried out in accordance with the Helsinki Declaration of 1975 , as revised in 2008, and the Nuremberg Code 1946. The present study was randomised, double-blind, cross-over, placebocontrolled intervention with two phases. Each phase ran for 4 weeks with 2 weeks of wash-out period between the phases. The duration of intervention of 4 weeks/phase was chosen for this study as the concentration of $\mathrm{AFB}_{1}-N^{7}$-guanine adduct was found to reduce significantly as early as during the $3 \mathrm{rd}$ week of intervention with probiotics ${ }^{(18)}$. In fact, its concentration reduced by $55 \%$ after 5 weeks of intervention ${ }^{(18)}$. Although a longer period of intervention is recommended, such trials can be costly and require high compliance from the subjects.

\section{Sample size rationale}

Data from an intervention study using a mixture of probiotics to reduce the concentrations of the $\mathrm{AFB}_{1}-N^{7}$-guanine adduct ${ }^{(18)}$ were referred to calculate the sample size. Following a 5-week intervention study, the concentrations of the $\mathrm{AFB}_{1}-N^{7}$-guanine adduct were reduced in the probiotic group, as the mean $\mathrm{AFB}_{1}$ $N^{7}$-guanine adduct was $0.19 \mathrm{ng} / \mathrm{ml}$ compared with the placebo group of $0.46 \mathrm{ng} / \mathrm{ml}$. Based on this information, the mean difference between the groups (d) of $0.27 \mathrm{ng} / \mathrm{ml}$ was obtained. The pool standard deviation $\left(\mathrm{SD}_{\text {pooled }}\right)$ at baseline was used as the best alternate standard deviation for the sample size calculation according to the formula by Rosnow \& Rosenthal ${ }^{(40)}$, and the calculated $\mathrm{SD}_{\text {pooled }}$ was $1 \cdot 11$. The value was then used to 
estimate within-subject variance $\left(\mathrm{SD}_{w}\right)$ for a cross-over study according to the formula $\left(\mathrm{SD}_{w}=\mathrm{SD}_{\text {pooled }} \times(1-\rho)\right)$, where $\rho$ is the Pearson's correlation coefficient estimated between two measures on the same subject. Assuming that there is a relatively modest correlation of $0.5(\rho=0.5)$, the $\mathrm{SD}_{w}$ would be half of the $\mathrm{SD}_{\text {pooled }}(1.11 \times(1-0.5)=0.555)^{(41)}$. Based on a formula for cross-over studies ${ }^{(41)}$ and using the values of $d$ and $\mathrm{SD}_{w}$, with $\alpha$ of 0.05 and power of $80 \%$, the required sample size was sixty-six subjects. To allow for a drop-out rate of $10 \%$ a total of seventy-two subjects were needed from the pool of subjects who participated in the screening and had detectable levels of urinary $\mathrm{AFM}_{1}$.

\section{Study population}

Subjects were recruited from among the employees at a faculty in UPM. Before the start of the intervention, a screening process was conducted and 160 subjects were recruited, for which the data have been published elsewhere ${ }^{(20)}$. The inclusion criteria for the intervention study were as follows: subjects with detectable levels of urinary $\mathrm{AFM}_{1}(>0.005 \mathrm{ng} / \mathrm{ml})$, healthy with no chronic diseases, not pregnant or planning to get pregnant and voluntary participation. Moreover, subjects who were allergic to fermented milk containing probiotic bacteria, lactose intolerant and with gastric problems or liver and kidney injuries were excluded. As the selection of subjects was based on those exposed to aflatoxin through the detection of urinary $\mathrm{AFM}_{1}$, they did not represent the general aflatoxin exposure in Malaysia.

A total of ninety-eight from 160 subjects involved in the screening stage had detectable levels of $\mathrm{AFM}_{1}$, and seventy-six subjects had $\mathrm{AFM}_{1}>0.005 \mathrm{ng} / \mathrm{ml}$. The subjects' medical history was evaluated and none of them had any chronic disease, allergy to fermented milk (contained probiotics) and lactose intolerance. Two subjects were excluded due to pregnancy and three subjects did not agree to participate in the intervention. Finally, only seventy-one subjects agreed to participate in the intervention. Signed informed consent was obtained before the start of the intervention. Subjects were randomly divided into two groups. As the total number of subjects was not even (i.e. seventy-one subjects), one group had thirty-six subjects and the other had thirty-five subjects. Subjects provided blood samples for the analysis of liver and kidney functions before the intervention began.

\section{Study protocol}

Before the start of the intervention, a controller (a third party who was not involved in the study) was appointed to hold the information on the types of treatment (probiotic or placebo drinks) that each group will receive during the intervention. Researchers and subjects were blinded and the controller determined the order of interventions ((1st (probiotic) washout - 2nd (placebo)) or (1st (placebo) - washout - 2nd (probiotic))) using colour code - namely, Blue and Yellow. For the first 4 weeks of the intervention (1st phase), one group was supplied with fermented milk drinks containing LcS (probiotic drinks) and the other group with placebo drinks. After 2 weeks of wash-out period, the intervention was crossed over, where subjects who received placebo drinks before the wash-out period were given probiotic drinks and vice versa and the intervention continued for another 4 weeks (2nd phase).

To ensure compliance, both drinks were given to the subjects on a daily basis twice a day (after breakfast and lunch). However, for weekend consumption, four bottles (probiotic or placebo drinks) were given on every Friday afternoon. The drinks were given in an ice box to maintain the refrigerated temperature. To ensure that subjects consumed the drinks and complied with the study protocol, a few reminders were made by calling and/or texting the subjects during the weekend.

Throughout the intervention, subjects were asked to consume their normal diets. Samples $(5 \mathrm{ml})$ of fasting blood and morning urine were collected at baseline and every 2 weeks (2nd, 4th, 6th, 8th and 10th week). Serum was separated from the blood by centrifugation at $3000 \mathrm{~g}$ for $10 \mathrm{~min}$ and maintained at $-80^{\circ} \mathrm{C}$. An aliquot of $15 \mathrm{ml}$ urine was also maintained at $-80^{\circ} \mathrm{C}$.

Subjects' food intake was examined using a 2-d food record. Subjects were taught by the researchers and enumerators to record their food intakes properly. They were asked to record details such as the type and amount of foods/drinks, brand, preparation methods and recipes in a booklet provided to them. Household measuring cups were also provided to the subjects to assist the recording process. The food record was collected when the subjects gave their blood and urine samples, and it was examined and checked by enumerators to make sure that they had recorded their food intake properly. At the end of each phase, subjects also received an FFQ comprised of several food items such as cereals, nuts, milk and dairy products and spices that are frequently reported in the literature to be contaminated with aflatoxin. Subjects were required to tick their frequency of intakes during the 4 -week intervention in both phases based on seven scales - namely, '2-3 times/d', 'once a d', '2-3 times/week', 'once a week', '2-3 times/month', 'once a month' or 'not eating' in order to study the frequency of food intakes between the two phases.

\section{Probiotic and placebo drinks}

Both probiotic and placebo drinks were prepared in a plastic bottle with a volume of $80 \mathrm{ml}$ by Yakult (Malaysia) Sdn. Bhd. The probiotic and placebo drinks were identical in appearance, taste and colour. The ingredients were fructose, maltitol, skimmed milk powder, glucose and permitted flavouring. The manufacturer confirmed that the probiotic drinks contained at least $3.0 \times 10^{10}$ colony-forming units (CFU) of LCS, whereas the placebo drinks did not contain any probiotic bacteria. Therefore, the only difference between these two drinks was the presence or absence of LcS.

\section{Analysis of the 2-d food record}

Nutrition analysis software, Nutritionist Pro $^{\mathrm{TM}}$ Diet Analysis (Axxya Systems) with food data bank from the USA, was used to analyse the food records collected from the subjects. The reference data used were the Nutrient Composition of Malaysian Foods (4th edition) ${ }^{(42)}$, which was more representative 
of local foods compared with other sources abroad. The total energy intake was also calculated for carbohydrates, proteins and fat.

\section{Analysis of the FFQ}

Two sets of FFQ were given to the subjects in order to study the frequency of food intake between the two phases based on seven scales as mentioned earlier. A score of 6 for ' $2-3$ times/d' to 0 for 'not eating' was computed for each scale to estimate the frequency of food intake of the subjects during the intervention. The higher score computed from the FFQ indicated that the foods were consumed more frequently and vice versa.

\section{Analysis of serum aflatoxin $B_{1}$-lysine adduct}

The concentrations of serum $\mathrm{AFB}_{1}$-lys were measured as described by Mohd Redzwan et al. ${ }^{(38)}$. In brief, serum was digested with PRONASE ${ }^{\circledR}$ Protease (Calbiochem) for $3 \mathrm{~h}$ at $37^{\circ} \mathrm{C}$, followed by purifications steps using Oasis ${ }^{\circledR}$ MAX Cartridge (Waters). The digested sample was allowed to pass the cartridge by gravity, followed by sequential washing steps with HPLC grade water (J.T. Baker), 70 \% HPLC grade methanol (Honeywell Burdick \& Jackson) in water, 1\% ammonium hydroxide (EMD Chemicals Inc.) in methanol and $100 \%$ HPLC grade methanol. $\mathrm{AFB}_{1}$-lys was eluted with $2 \%$ formic acid (Fluka) in methanol, evaporated to dryness and reconstituted with $25 \%$ HPLC grade methanol in water before HPLC analysis. A reversed-phase HPLC analysis was carried out using a 1200 series of liquid chromatography system with a quaternary pump (Agilent Technologies). The chromatographic separation was performed using a ZORBAX $^{\circledR}$ Eclipse XDB-C18 column, $250 \times 4.6 \mathrm{~mm}, 5 \mu \mathrm{m}$ (Agilent Technologies), connected to a guard column (Security Guard ${ }^{\mathrm{TM}}$ ). The mobile phases were 20 mm-ammonium phosphate monobasic, $\mathrm{pH} 7 \cdot 2$, and HPLC grade methanol, and the separation was carried out in a linear gradient profile. A sample of $100 \mu \mathrm{l}$ was injected to the HPLC system with a flow rate of $1 \mathrm{ml} / \mathrm{min}$ and the peak of $\mathrm{AFB}_{1}$-lys was detected in a fluorescence detector (FLD) with wavelength of $405 \mathrm{~nm}$ (excitation) and $470 \mathrm{~nm}$ (emission). To identify the peak of $\mathrm{AFB}_{1}$-lys adduct in the samples, blank human serum spiked with $\mathrm{AFB}_{1}$-lys standard (courtesy of Prof Wang's Laboratory) was used as the control. The limit of detection (LOD) was $0.05 \mathrm{ng} / \mathrm{ml} \mathrm{AFB}_{1}$-lys. The peak of $\mathrm{AFB}_{1}$-lys was detected at a retention time of $13.1 \mathrm{~min}$. Serum $\mathrm{AFB}_{1}$-lys was expressed as $\mathrm{pg} / \mathrm{mg}$ ALB.

\section{Analysis of urinary aflatoxin $M_{1}$}

The extraction procedures and analysis of urinary $\mathrm{AFM}_{1}$ were based on the methods of Mohd Redzwan et al. ${ }^{\text {(43) }}$. In brief, $5 \mathrm{ml}$ of urine was adjusted to an acidic $\mathrm{pH}$ with $0.5 \mathrm{ml}$ of $1 \mathrm{~m}$-ammonium formate ( $\mathrm{pH} 4.5$ ) (Sigma-Aldrich) and the volume was increased to $10 \mathrm{ml}$ with ultrapure water obtained from Milli-Q system (Thermo Scientific Barnstead) and vortexed. Subsequently, the sample was passed by gravity through the Immunoaffinity Column (IAC), EASI-EXTRACT ${ }^{\circledR}$ AFLATOXIN (R-Biopharm Rhône Ltd) followed by washing twice with $10 \mathrm{ml}$ PBS ( $\mathrm{pH}$ 7.4). Air pressure was applied to remove any residual $\mathrm{PBS}$, and $\mathrm{AFM}_{1}$ was eluted from the IAC at a flow rate of $1 \mathrm{drop} / \mathrm{s}$ with $2 \mathrm{ml}$ HPLC grade methanol (Merck) and collected in an amber glass vial (Fisher Scientific). The eluate was evaporated to dryness with purified $\mathrm{N}$ gas and reconstituted with $500 \mu \mathrm{l}$ mobile phase. A reversed-phase ultra HPLC (UHPLC) analysis was carried out using an Agilent 1290 Infinity liquid chromatography system with a binary pump and an auto sampler coupled with an FLD (Agilent Technologies). The column used was the ZORBAX RRHD Eclipse Plus C18 column, $150 \times 2 \cdot 1 \mathrm{~mm}, 1.8 \mu \mathrm{m}$, connected to a UHPLC fast guard column, Eclipse Plus C18, 2.1 ×5.5 mm (Agilent Technologies). The mobile phase was water-acetonitrile-methanol $(6 \cdot 5: 2 \cdot 5: 1$, $\mathrm{v} / \mathrm{v} / \mathrm{v} \%$ ) and was of HPLC grade (Merck). The chromatographic separation was performed isocratically at a flow rate of $0.2 \mathrm{ml} / \mathrm{min}$, with $20 \mu \mathrm{l}$ volume of injection, and the column's temperature was maintained at $40^{\circ} \mathrm{C}$. The wavelength of FLD was fixed at 365 and $435 \mathrm{~nm}$ for excitation and emission, respectively. For quality control purpose, $\mathrm{AFM}_{1}$ standard (Trilogy Analytical Laboratory Inc.) and/or spiked $\mathrm{AFM}_{1}$ urine were injected for every six injections (i.e. six samples) during the analysis in order to assure the correct identification of $\mathrm{AFM}_{1}$ peak in the samples. The LOD was $0.018 \mathrm{ng} / \mathrm{ml} \mathrm{AFM}$. $\mathrm{AFM}_{1}$ was eluted at $5.6 \mathrm{~min}$, and urinary $\mathrm{AFM}_{1}$ was expressed as $\mathrm{pg} / \mu \mathrm{mol}$ creatinine.

\section{Statistical analyses}

Data were analysed using SPSS version 17.0 software (SPSS Inc.). Data from both the groups (Blue and Yellow) were combined and analysed. As the study design was a cross-over study and each subject consumed probiotic and placebo drinks throughout the duration of the intervention, data were also analysed individually to see whether the order of probiotic intervention had an impact on the outcomes. Reduction of serum $\mathrm{AFB}_{1}$-lys and urinary $\mathrm{AFM}_{1}$ was the primary outcome of this study. In addition, the difference in the concentrations of serum $\mathrm{AFB}_{1}$-lys and urinary $\mathrm{AFM}_{1}$ between the treatments was the secondary outcome investigated here.

Before further analyses were conducted, data were checked for normality. For data that were normally distributed - that is, energy intake, macronutrients intake, dietary fibre intake and serum $\mathrm{AFB}_{1}$-lys - parametric analysis was performed. Paired sample $t$ test was used to compare all the above variables between each time point. Besides, independent $t$ test was used to compare the food intake between subjects in the Blue and Yellow groups when they were given probiotic drinks. As for the FFQ administered during the intervention, paired sample $t$ test was used to compare the frequency of intakes within the groups between the two treatments, whereas independent $t$ test was used to compare the frequency of intakes between the groups for each treatment. In order to study the effect of treatment over 4 weeks of intervention on the concentration of serum $\mathrm{AFB}_{1}$-lys, ANOVA for repeated measurements was applied.

Conversely, data of urinary $\mathrm{AFM}_{1}$ were not normally distributed, and therefore non-parametric analysis was used. The Wilcoxon signed-rank test was used to compare the 
concentrations of urinary $\mathrm{AFM}_{1}$ between each time point. To investigate the effect of treatments over 4 weeks of intervention on the concentration of urinary $\mathrm{AFM}_{1}$, the Friedman's test was used. On the other hand, correlation analyses were carried out between aflatoxin biomarkers and foods that are possible sources of aflatoxins and also between subjects' food consumption. The level of significance was assigned at $P$ value $<0 \cdot 05$. After all the analyses were completed, the orders of intervention ((1st (probiotic) - washout -2 nd (placebo)) or (1st (placebo) - washout - 2nd (probiotic))) were revealed by the controller to the researchers.

\section{Results}

\section{Baseline characteristics of the subjects}

The recruitment of subjects through the screening stage began in January 2012 and was completed in March 2012, and some of the data have been published elsewhere ${ }^{(7)}$. Of the seventy-two subjects required, only seventy-one were successfully recruited, and $50.7 \%$ of them were males $(n$ 36) and the rest were females ( $n$ 35). The mean age of the subjects was 34.34 (SD 9.70) years, ranging from 23 to 57 years, and was not significantly different between males (34.08 (SD 10.35) years) and females (34.60 (sD 9.12) years). Overall, subjects' BMI was $25 \cdot 26$ $(\mathrm{sD} 5.50) \mathrm{kg} / \mathrm{m}^{2}$. Females $\left(25.58(\mathrm{sD} 5.50) \mathrm{kg} / \mathrm{m}^{2}\right.$ ) had slightly higher BMI than males $(24.95$ (SD 5.58$) \mathrm{kg} / \mathrm{m}^{2}$ ) but the difference was not significant. In all, thirty-three subjects were overweight and obese and had BMI $>25 \mathrm{~kg} / \mathrm{m}^{2}$. Analysis of aspartate aminotransferase, alanine transaminase, alkaline phosphatase, $\gamma$-glutamyl transpeptidase, total bilirubin, blood urea nitrogen and creatinine indicated that subjects had normal liver and kidney functions before the start of the intervention.

The subjects' socio-demographic characteristics, urinary $\mathrm{AFM}_{1}$ concentration and the intake of food groups that are possible sources of aflatoxin measured during the screening stage are shown in Table 1. There were no significant differences in socio-demographic characteristics between the two groups. No differences in the intakes of food groups known to be the most common sources of dietary aflatoxin exposure were also observed between the groups. Based on findings obtained during the screening stage, all the subjects had similar intake of foods and were assumed to have homogeneous dietary exposure to aflatoxin before the start of the intervention.

\section{Adherence to the study protocol}

All the subjects who participated in this study completed both phases of the intervention. Although some of them had reported taking antibiotics during the intervention ( $n$ 8), they were still provided with either probiotic or placebo drinks during the intervention period with the intention to treat. A flow diagram reflecting the subjects' passage during the intervention is illustrated in Fig. 1. Five subjects were taking antibiotics when they were being provided the probiotic drinks. Finally, considering the effect of antibiotics on the activity of probiotic bacteria, data from only sixty-six subjects $(71-5$; thirty-four from the Blue group and thirty-two from the Yellow group) were used for further statistical analyses.

\section{Frequency of intakes of foods that are possible sources of aflatoxin}

Table 2 shows the intake frequency of fifteen food items that are possible sources of aflatoxin obtained through an FFQ given to the subjects at the end of each phase. The outputs measured from the FFQ were the frequency of intake and not the amount of foods, which was different from the FFQ survey conducted during the screening stage. Overall, subjects had significantly $(P<0.05)$ higher frequency of breads and spices and herbs intakes when they were supplemented with probiotic drinks than during the placebo intervention period. As for the within-group

Table 1. Subjects' socio-demographic and data on food intake and urinary aflatoxin $M_{1}\left(A F M_{1}\right)$ obtained from the screening stage (Mean values and standard deviations)

\begin{tabular}{|c|c|c|c|c|}
\hline \multirow[b]{2}{*}{ Variables } & \multicolumn{2}{|c|}{ Blue } & \multicolumn{2}{|c|}{ Yellow } \\
\hline & Mean & SD & Mean & SD \\
\hline Total number of subjects & \multicolumn{2}{|c|}{35} & \multicolumn{2}{|c|}{36} \\
\hline Male & \multicolumn{2}{|c|}{15} & \multicolumn{2}{|c|}{21} \\
\hline Female & \multicolumn{2}{|c|}{20} & \multicolumn{2}{|c|}{15} \\
\hline Age (years) & 34.74 & 9.99 & 33.94 & 9.53 \\
\hline Body weight $(\mathrm{kg})$ & $67 \cdot 19$ & 14.53 & 65.09 & $18 \cdot 18$ \\
\hline Height (m) & 1.60 & 0.92 & 1.63 & 0.88 \\
\hline BMI $\left(\mathrm{kg} / \mathrm{m}^{2}\right)^{*}$ & $26 \cdot 16$ & 5.04 & $24 \cdot 39$ & $5 \cdot 84$ \\
\hline \multicolumn{5}{|l|}{ Median total intake $(\mathrm{g} / \mathrm{d}) \dagger$} \\
\hline Nuts and nut-based products & \multicolumn{2}{|c|}{$15 \cdot 76$} & \multicolumn{2}{|c|}{$15 \cdot 56$} \\
\hline Cereals and cereal-based products & \multicolumn{2}{|c|}{871.66} & \multicolumn{2}{|c|}{$768 \cdot 88$} \\
\hline Milk and dairy products & \multirow{2}{*}{\multicolumn{2}{|c|}{$\begin{array}{r}95.22 \\
7.99\end{array}$}} & \multirow{2}{*}{\multicolumn{2}{|c|}{$\begin{array}{r}78.96 \\
8.94\end{array}$}} \\
\hline Spices and herbs & & & & \\
\hline Urinary $\mathrm{AFM}_{1}$ (pg/ $/ \mu \mathrm{mol}$ creatinine) & $2 \cdot 38$ & $2 \cdot 13$ & 3.06 & 2.48 \\
\hline Assignment of treatment $\ddagger$ & \multicolumn{2}{|c|}{$A B$} & \multicolumn{2}{|c|}{ BA } \\
\hline
\end{tabular}

* $\mathrm{BMI}$ is calculated based on the formula (body weight $(\mathrm{kg}) /$ height $^{2}\left(\mathrm{~m}^{2}\right)$ ).

† Subjects' food intakes were obtained from the FFQ administered during the screening stage.

$\ddagger A B=(1$ st (probiotic) - washout $-2 n d($ placebo $)) ; B A=(1$ st (placebo $)-$ washout -2 nd (probiotic) $)$. 


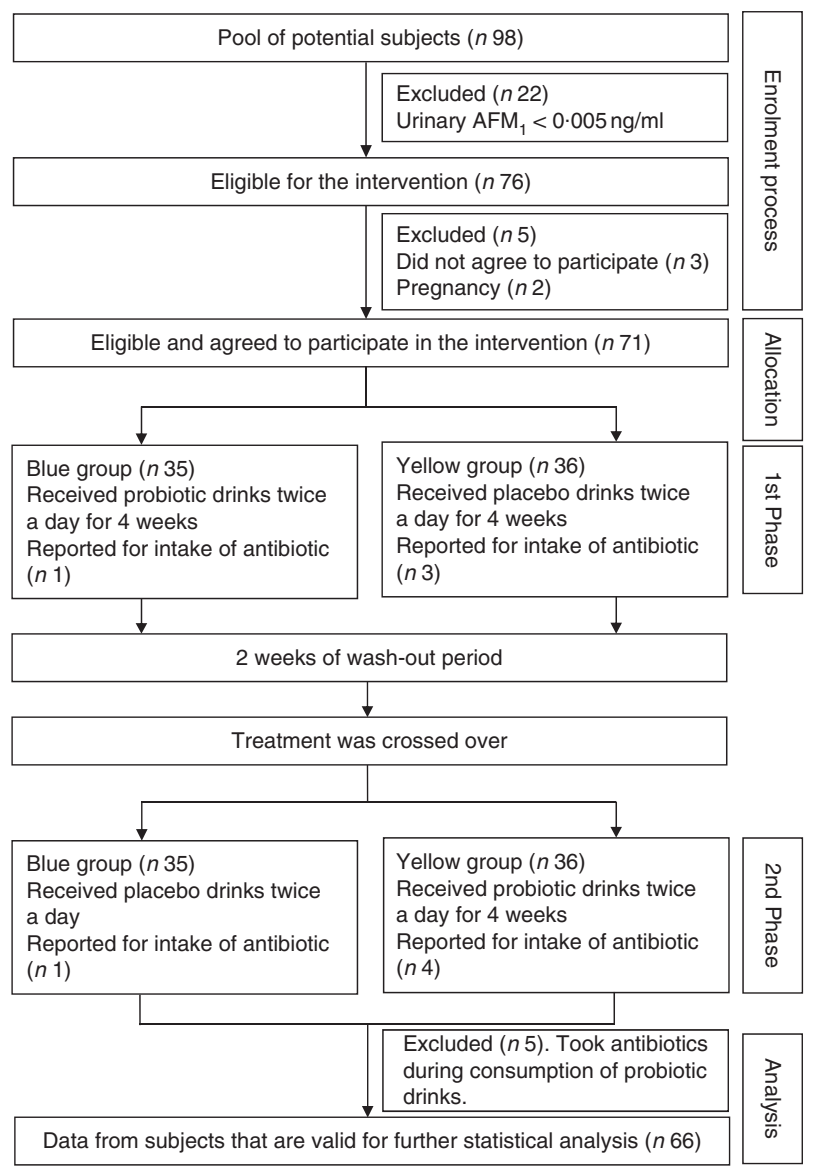

Fig. 1. Flow chart of subjects' progression in the intervention study. $A F M_{1}$, aflatoxin $\mathrm{M}_{1}$. analysis, no significant differences on the frequency of intakes were observed in the Blue group. On the other hand, subjects in the Yellow group had significantly $(P<0.05)$ higher frequency of breads and liquid milk intakes during the 4 weeks of intervention with the probiotic drinks than with the placebo drinks. Nevertheless, the frequency of intakes of these foods was not significantly different between the two groups when the subjects were supplemented with the probiotic and placebo drinks, respectively.

\section{Subjects' food consumption}

There were significant differences in energy and macronutrient intakes during the consumption of probiotic and placebo drinks, respectively (Table 3 ). While consuming the placebo drinks, the only difference observed was the intake of protein as subjects consumed significantly high-protein diets during the 4th week of intervention compared with the baseline. Conversely, energy and macronutrient intakes were found to be significantly higher during the 4 th week of probiotic intervention compared with the baseline. To support these findings, within-group analysis was performed and the results are presented in Table 4.

In the Blue group, the intakes of energy, macronutrients and dietary fibre were not significantly different throughout the 4-week intervention period, either with probiotic or placebo drinks. However, the 4 th week carbohydrate intake was significantly higher compared with the baseline intake when the subjects consumed probiotic drinks. In contrast, subjects in the Yellow group had significantly higher intakes of protein during the 4 th week of intervention with placebo compared with the

Table 2. Food frequency intakes of foods that are possible sources of aflatoxin during the intervention

(Mean values and standard deviations)

\begin{tabular}{|c|c|c|c|c|c|c|c|c|c|c|c|c|c|c|c|}
\hline \multirow[b]{4}{*}{ Food items } & \multicolumn{15}{|c|}{ Food frequency† } \\
\hline & \multicolumn{5}{|c|}{ Blue group $(n 34) \ddagger$} & \multicolumn{5}{|c|}{ Yellow group ( $n$ 32) $\ddagger$} & \multicolumn{5}{|c|}{ Overall ( $n$ 66) } \\
\hline & \multicolumn{2}{|c|}{ Probiotic } & \multicolumn{2}{|c|}{ Placebo } & \multirow[b]{2}{*}{$P \S$} & \multicolumn{2}{|c|}{ Probiotic } & \multicolumn{2}{|c|}{ Placebo } & \multirow[b]{2}{*}{$P \S$} & \multicolumn{2}{|c|}{ Probiotic } & \multicolumn{2}{|c|}{ Placebo } & \multirow[b]{2}{*}{$P \S$} \\
\hline & Mean & $\mathrm{SD}$ & Mean & SD & & Mean & SD & Mean & $\mathrm{SD}$ & & Mean & SD & Mean & SD & \\
\hline Rice and glutinous rice & 1.65 & 0.44 & 1.59 & 0.47 & 0.562 & $1 \cdot 70$ & 0.60 & 1.65 & 0.46 & 0.546 & 1.65 & 0.45 & 1.65 & 0.54 & 0.917 \\
\hline Noodles and pasta & 1.90 & 0.90 & 1.87 & 0.62 & 0.833 & 1.77 & 0.70 & 1.66 & 0.82 & 0.440 & 1.78 & 0.86 & 1.82 & 0.65 & 0.700 \\
\hline $\begin{array}{l}\text { Breads (including buns, white, wheat, } \\
\text { wholemeal and traditional breads) }\end{array}$ & 2.66 & $1 \cdot 30$ & $2 \cdot 75$ & $1 \cdot 12$ & 0.557 & 2.51 & 0.80 & $2 \cdot 17$ & 0.74 & $0.018^{*}$ & $2 \cdot 41$ & 1.09 & $2 \cdot 64$ & 0.98 & $0.049^{*}$ \\
\hline Cereals (including ready-to-eat cereals) & 1.29 & $1 \cdot 34$ & $1 \cdot 16$ & $1 \cdot 12$ & 0.579 & 0.77 & 0.95 & 0.89 & $1 \cdot 11$ & 0.501 & $1 \cdot 10$ & $1 \cdot 24$ & 0.97 & 1.08 & 0.393 \\
\hline Maize & 0.91 & 0.71 & 0.91 & 0.93 & 1.000 & $1 \cdot 16$ & 1.01 & 0.97 & 0.87 & 0.296 & 0.94 & 0.78 & 1.03 & 0.98 & 0.443 \\
\hline All types of nuts (except peanuts) & 1.94 & 1.84 & 1.52 & 0.99 & 0.210 & $1 \cdot 19$ & $1 \cdot 15$ & 1.31 & $1 \cdot 20$ & 0.645 & 1.63 & 1.58 & 1.36 & 1.08 & 0.203 \\
\hline Peanuts & $1 \cdot 74$ & 1.48 & 1.44 & 1.07 & 0.193 & $1 \cdot 75$ & $1 \cdot 32$ & 1.56 & $1 \cdot 16$ & 0.440 & 1.65 & 1.33 & 1.59 & $1 \cdot 20$ & 0.713 \\
\hline Peanut butter & 0.65 & $1 \cdot 18$ & 0.65 & $1 \cdot 12$ & 1.000 & 0.91 & 1.40 & 0.81 & $1 \cdot 15$ & 0.447 & 0.73 & $1 \cdot 16$ & 0.77 & $1 \cdot 26$ & 0.721 \\
\hline Nut-based foods & $1 \cdot 13$ & 0.61 & $1 \cdot 14$ & 0.56 & 0.869 & $1 \cdot 21$ & 0.60 & $1 \cdot 30$ & 0.55 & 0.324 & $1 \cdot 21$ & 0.58 & $1 \cdot 18$ & 0.58 & 0.582 \\
\hline Chocolate and malt drinks & 2.42 & $1 \cdot 22$ & 2.34 & 1.24 & 0.557 & 2.54 & 1.07 & $2 \cdot 36$ & 1.08 & 0.114 & $2 \cdot 39$ & $1 \cdot 14$ & 2.44 & $1 \cdot 16$ & 0.603 \\
\hline Liquid milk (fresh/UHT/condensed/evaporated) & 1.77 & $1 \cdot 15$ & 2.00 & 1.14 & 0.302 & 1.94 & $1 \cdot 23$ & 1.67 & 1.07 & $0.040^{*}$ & 1.72 & $1 \cdot 11$ & 1.97 & $1 \cdot 17$ & 0.053 \\
\hline Powdered milk & $1 \cdot 71$ & $1 \cdot 78$ & 1.59 & 1.78 & 0.743 & 1.34 & 2.07 & $1 \cdot 28$ & 2.05 & 0.701 & 1.50 & 1.92 & 1.47 & 1.92 & 0.879 \\
\hline Cheese & $1 \cdot 26$ & $1 \cdot 33$ & 1.29 & $1 \cdot 19$ & 0.913 & 1.09 & 1.05 & 1.03 & 0.93 & 0.737 & $1 \cdot 15$ & $1 \cdot 15$ & $1 \cdot 20$ & $1 \cdot 21$ & 0.782 \\
\hline Dairy products & 1.38 & 1.37 & $1 \cdot 12$ & 1.45 & 0.369 & 0.88 & 1.29 & 0.84 & 0.95 & 0.879 & $1 \cdot 12$ & $1 \cdot 21$ & 1.00 & $1 \cdot 37$ & 0.500 \\
\hline $\begin{array}{l}\text { Spices and herbs (including chili, curry, } \\
\text { turmeric, black and white pepper powder) }\end{array}$ & $2 \cdot 79$ & $1 \cdot 30$ & 2.55 & 1.29 & 0.186 & $2 \cdot 67$ & $1 \cdot 16$ & $2 \cdot 89$ & 1.06 & 0.129 & $2 \cdot 84$ & $1 \cdot 18$ & $2 \cdot 61$ & $1 \cdot 22$ & $0.046^{\star}$ \\
\hline
\end{tabular}

UHT, ultra high temperature pasteurized.

${ }^{*} P<0.05$.

† Food frequency scores range from 0 (not eating at all) to 6 (eat 2-3 times/d).

¥ No significant differences in food frequency between the groups, respectively, during the probiotic and placebo consumption period.

$\S P$ values obtained from paired samples $t$ test. 
Effect of probiotics on aflatoxin biomarkers

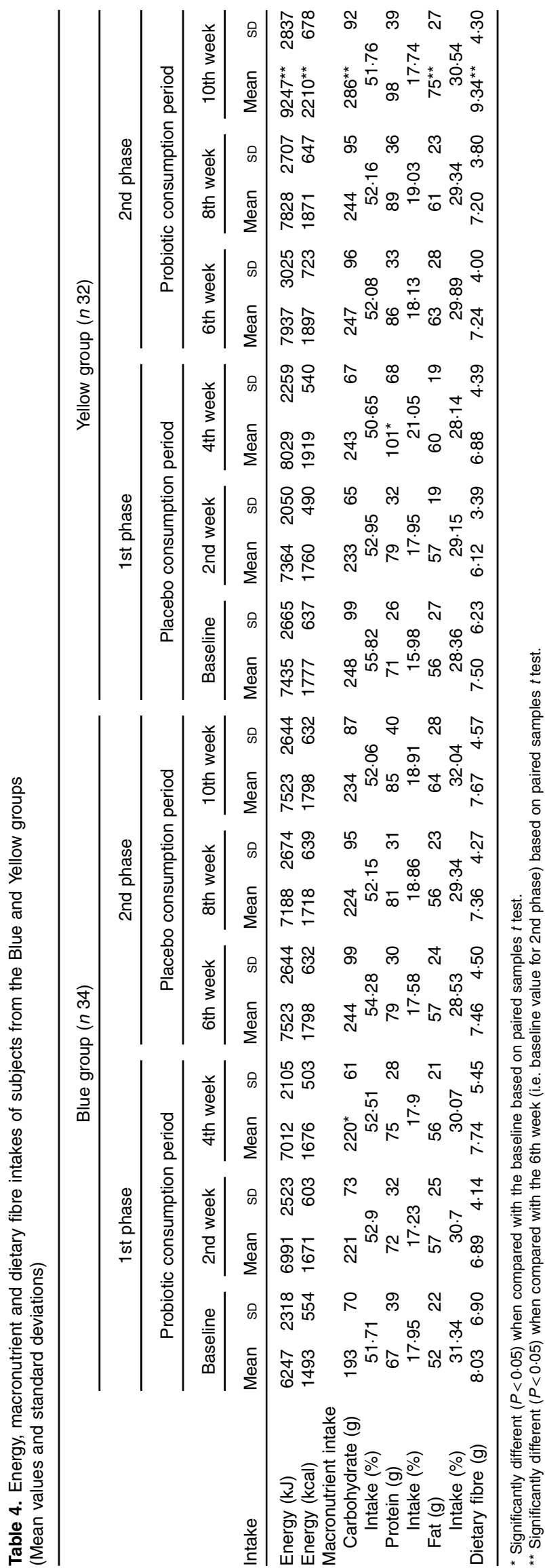


Table 5. Comparison of energy, macronutrients and dietary fibre intakes during the probiotic consumption period

(Mean values and standard deviations)

\begin{tabular}{|c|c|c|c|c|c|}
\hline \multirow[b]{2}{*}{ Intake } & \multicolumn{2}{|c|}{ Blue group $(n 34)^{\star}$} & \multicolumn{2}{|c|}{ Yellow group $(n$ 32) $\dagger$} & \multirow[b]{2}{*}{$P$} \\
\hline & Mean & SD & Mean & SD & \\
\hline \multicolumn{6}{|l|}{ Energy (kJ) } \\
\hline Baseline & 6247 & 2318 & 7937 & 3025 & \\
\hline 2nd week & 6991 & 2527 & 7828 & 2707 & \\
\hline 4th week & 7012 & 2109 & 9247 & 2837 & \\
\hline \multicolumn{6}{|l|}{ Energy (kcal) } \\
\hline Baseline & 1493 & 554 & 1897 & 723 & $0.013 \ddagger$ \\
\hline 2nd week & 1671 & 604 & 1871 & 647 & 0.198 \\
\hline 4th week & 1676 & 504 & 2210 & 678 & $0.001 \ddagger$ \\
\hline \multicolumn{6}{|c|}{ Carbohydrate (g) } \\
\hline Baseline & 192.93 & $70 \cdot 16$ & $247 \cdot 28$ & $95 \cdot 66$ & $0.010 \ddagger$ \\
\hline 2nd week & $221 \cdot 11$ & $72 \cdot 81$ & 244.73 & 94.89 & 0.259 \\
\hline 4th week & $219 \cdot 63$ & $61 \cdot 13$ & $286 \cdot 47$ & 91.78 & $0.001 \ddagger$ \\
\hline \multicolumn{6}{|l|}{ Protein (g) } \\
\hline Baseline & $66 \cdot 60$ & 38.63 & 86.07 & 33.41 & $0.033 \ddagger$ \\
\hline 2nd week & $72 \cdot 25$ & 31.92 & 88.91 & 36.06 & 0.051 \\
\hline 4th week & $75 \cdot 25$ & $28 \cdot 11$ & $98 \cdot 24$ & 39.01 & $0.008 \ddagger$ \\
\hline \multicolumn{6}{|l|}{ Fat (g) } \\
\hline Baseline & 51.56 & 21.64 & 63.32 & 28.42 & 0.062 \\
\hline 2nd week & $57 \cdot 33$ & 24.73 & 60.91 & 22.54 & 0.541 \\
\hline 4th week & $55 \cdot 77$ & $21 \cdot 31$ & 75.49 & $26 \cdot 72$ & $0.001 \ddagger$ \\
\hline \multicolumn{6}{|c|}{ Dietary fibre (g) } \\
\hline Baseline & 8.03 & $6 \cdot 90$ & $7 \cdot 24$ & 4.00 & 0.572 \\
\hline 2nd week & 6.89 & 4.14 & $7 \cdot 20$ & 3.80 & 0.754 \\
\hline 4th week & $7 \cdot 74$ & 5.45 & $9 \cdot 34$ & $4 \cdot 30$ & 0.192 \\
\hline
\end{tabular}

* Consumed probiotic drinks before the wash-out period (1st phase).

$\dagger$ Consumed probiotic drinks after the wash-out period (2nd phase).

$\ddagger P$ values are obtained from the independent $t$ test indicating significant difference.

baseline intakes. More prominent differences were observed during the 2nd phase - that is, during the consumption of probiotic drinks. The energy intake was significantly higher at the last week of intervention, which saw an increase of $16.4 \%$ energy intake from $7937 \mathrm{~kJ}(1897 \mathrm{kcal})$ to $9247 \mathrm{~kJ}(2210 \mathrm{kcal})$. Regarding macronutrient intakes, the intakes of carbohydrates and fat were significantly higher compared with the 6th week intakes (i.e. baseline intake for 2nd phase). In addition, the subjects had significantly higher dietary fibre intakes compared with the baseline intakes (Table 4).

We carried out further analysis to compare the food intakes of subjects in the Yellow and Blue groups during the probiotic consumption period. We found that subjects in the Yellow groups had significantly higher intake of macronutrients compared with subjects in the Blue group (Table 5).

\section{Modulation of serum aflatoxin $B_{1}$-lysine adduct}

Overall, we collected 426 serum samples (seventy-one subjects $\times 6$ times of collection) and all of them had detectable concentrations of $\mathrm{AFB}_{1}$-lys. We found no significant difference in the concentrations of $\mathrm{AFB}_{1}$-lys during the 4 weeks of intervention with probiotic and placebo drinks. However, further analysis conducted within the groups showed some promising findings. As for subjects in the Blue group, the consumption of placebo did not change the concentrations of $\mathrm{AFB}_{1}$-lys. Nevertheless, when the subjects were given probiotic drinks, the outputs of ANOVA for repeated measurements indicated that the concentrations of $\mathrm{AFB}_{1}$-lys were significantly different $\left(F_{2,66}=4.283 ; P=0.035\right.$, partial $\left.\eta^{2}=0.115\right)$ during the 4 weeks of intervention. The pair-wise comparison further showed that the concentrations were significantly lower after 2 weeks of intervention $(P=0.048)$, with a percentage reduction of $17.63 \%$. Although not significant $(P=0.332)$, the concentrations of $\mathrm{AFB}_{1}$-lys at the end of the intervention (4th week) was lower compared with the baseline. In fact, the 4th week concentrations of the two treatments were significantly different $(P=0.005) \quad(6.35 \quad(\mathrm{sD} 2.41) \mathrm{pg} / \mathrm{mg}$ ALB, placebo $v .5 .48$ (sD 2.25$) \mathrm{pg} / \mathrm{mg}$ ALB, probiotic). The same analyses were performed for data obtained from subjects in the Yellow group as well, and we found no significant differences in the concentrations of $\mathrm{AFB}_{1}$-lys for both treatments over the 4 weeks of intervention (Table 6).

\section{Modulation of urinary aflatoxin $M_{1}$}

A total of 426 urine samples were collected, but only 153 samples were positive for $\mathrm{AFM}_{1}$. Due to the high rate of non-detectable values of $\mathrm{AFM}_{1}$ in the urine samples, the concentration of negative samples was expressed as half of $\mathrm{LOD}^{(18)}$ (i.e. $1 / 2 \times 0.018 \mathrm{ng} / \mathrm{ml}=0.009 \mathrm{ng} / \mathrm{ml}$ ). Overall, the intervention did not change the concentrations of urinary $\mathrm{AFM}_{1}$. In addition, within-group analysis also indicated no significant differences in the median urinary $\mathrm{AFM}_{1}$ concentration among subjects in the Blue group across the three different time periods (i.e. baseline, 2nd and 4th week) when the subjects consumed the probiotic $\left(\chi^{2}=1.647, \mathrm{df}=2 ; P=0.439\right)$ or placebo drinks $\left(\chi^{2}=2.529, \mathrm{df}=2 ; P=0.282\right)$. Although not significant, a decreasing trend in median urinary $\mathrm{AFM}_{1}$ concentrations was observed between the 2nd and 4th week with probiotic intervention. A similar observation was found in the Yellow group when the subjects were given probiotic $\left(\chi^{2}=4.759, \mathrm{df}=2\right.$; $P=0.093)$ and placebo drinks $\left(\chi^{2}=1.688, \quad \mathrm{df}=2 ; \quad P=0.430\right)$ (Table 7).

\section{Association between aflatoxin biomarkers and frequency of intakes of foods that are possible sources of aflatoxin}

As shown in Table 8, several significant associations were found between aflatoxin biomarkers and the frequency of intakes of foods that are possible sources of aflatoxin. Significant and negative associations were found between the 2nd week $\mathrm{AFB}_{1}$-lys and the intake frequency of rice and glutinous rice $(r-0 \cdot 263)$, all types of nuts $(r-0 \cdot 266)$, chocolate and malt drinks $(r-0.258)$ and liquid milk $(r-0 \cdot 291)$, whereas the 2 nd week urinary $\mathrm{AFM}_{1}$ concentration was significantly correlated with the frequency of nut-based foods intake ( $r$ 0.258) during the probiotic consumption period. Conversely, the intake frequency of nuts-based foods and cheese, respectively, were the only foods items that significantly correlated with the baseline $(r 0 \cdot 271)$ and 4 th week $(r-0 \cdot 242)$ urinary $\mathrm{AFM}_{1}$ concentrations during the placebo consumption period.

Within-group analysis also showed some significant associations between the two studied variables. In the Blue group, the baseline $\mathrm{AFB}_{1}$-lys was significantly correlated with the intake 
Effect of probiotics on aflatoxin biomarkers

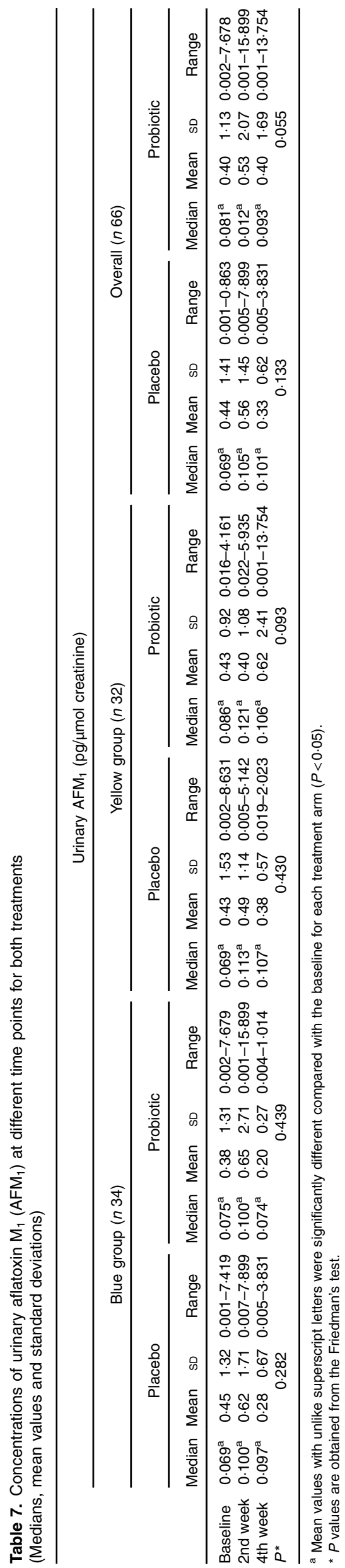




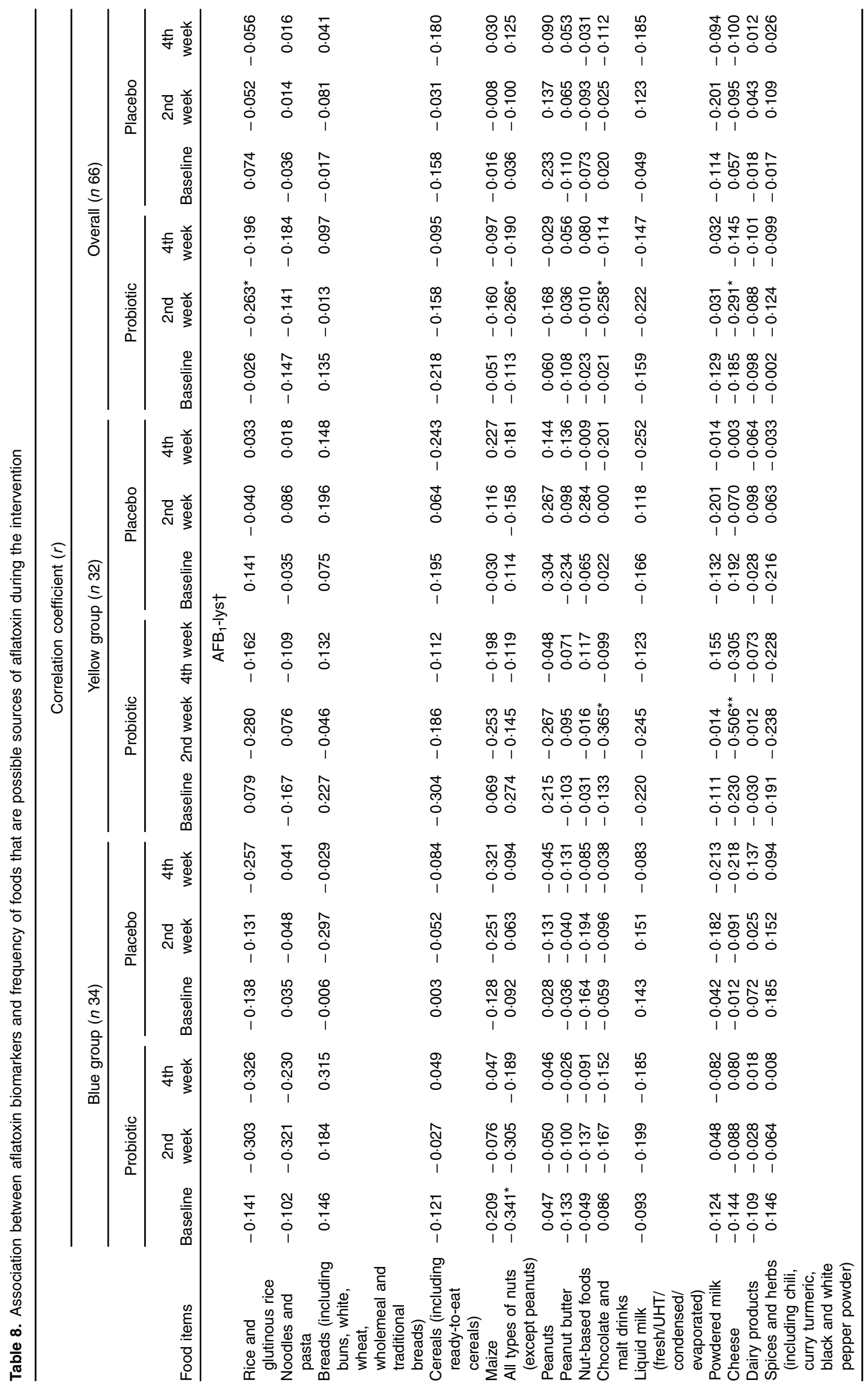




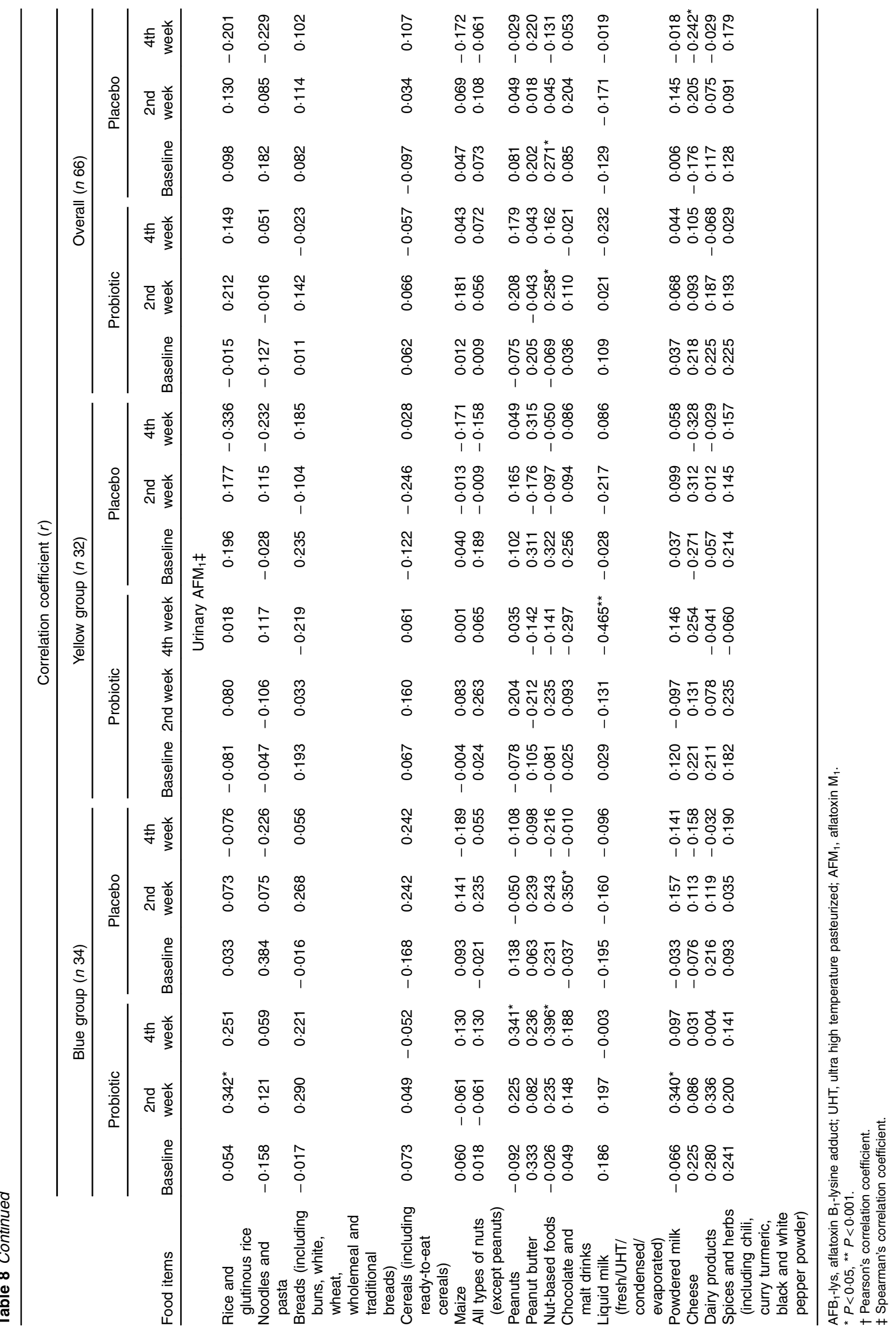


Table 9. Correlations between the 4th week aflatoxin biomarkers and macronutrients and dietary fibre intakes among subjects in the Yellow group during the probiotic consumption period $\dagger$

\begin{tabular}{|c|c|c|c|c|c|c|}
\hline \multirow[b]{3}{*}{ 4th week food consumption } & \multicolumn{6}{|c|}{ 4th week aflatoxin biomarkers } \\
\hline & \multicolumn{3}{|c|}{$\mathrm{AFB}_{1}$-lysine adduct } & \multicolumn{3}{|c|}{ Urinary $\mathrm{AFM}_{1}$} \\
\hline & Correlation coefficient & $P \ddagger$ & $P \S$ & Correlation coefficient & $P \ddagger$ & $P \S$ \\
\hline Carbohydrate & 0.312 & 0.082 & $0.041^{*}$ & 0.269 & 0.137 & 0.068 \\
\hline Protein & 0.303 & 0.092 & $0.046^{*}$ & 0.411 & $0.019^{*}$ & $0.010^{*}$ \\
\hline Fat & 0.144 & 0.431 & 0.215 & 0.309 & 0.086 & $0.043^{x}$ \\
\hline Dietary fibre & 0.208 & 0.254 & $0 \cdot 127$ & 0.330 & 0.065 & $0.033^{*}$ \\
\hline
\end{tabular}

$\mathrm{AFB}_{1}$-lys, aflatoxin $\mathrm{B}_{1}$-lysine adduct; $\mathrm{AFM}_{1}$, aflatoxin $\mathrm{M}_{1}$

${ }^{*} P<0.05$.

† Pearson's correlation analysis was conducted for correlation between AFB ${ }_{1}$-lys adduct and macronutrients and dietary fibre intakes, whereas Spearman's correlation analysis was performed for urinary $\mathrm{AFM}_{1}$ and macronutrients and dietary fibre intakes.

$\mp P$ value at two-tailed test.

$\S P$ value at one-tailed test. The test was conducted due to the non-normal distribution of urinary AFM $_{1}$.

frequency of all types of nuts $(r-0 \cdot 341)$, whereas the 2 nd week and 4th week urinary $\mathrm{AFM}_{1}$ concentrations, respectively, were significantly correlated with the intake frequency of two food items (2nd week: rice and glutinous rice, $r$ 0.342; powdered milk, $r 0.340$ and 4th week: peanut, $r 0.341$; nuts-based foods, $r$ 0.396) during the probiotic intervention period. Meanwhile, the intake frequency of noodles and pasta and chocolate and malt drinks during the placebo intervention period were found to be significantly correlated with the baseline $(r$ 0.384) and 4th week $\left(r\right.$ 0.310) urinary $\mathrm{AFM}_{1}$ concentrations, respectively. As for the Yellow group, we found that the 2nd week $\mathrm{AFB}_{1}$-lys level was significantly and inversely correlated with the intake frequency of chocolate and malt drinks $(r-0.365)$ and cheese $(r-0.506)$ when the subjects were supplemented with the probiotic drinks. In addition, the frequency of liquid milk consumption was also significantly correlated with the 4 th week urinary $\mathrm{AFM}_{1}$ concentration $(r-0.465)$ during the 4 weeks of probiotic intervention. Nonetheless, we did not find any significant correlations between the two studied variables during the placebo consumption period.

\section{Association between aflatoxin biomarkers and food consumption}

No significant associations between aflatoxin biomarkers and food consumption were found in the Blue group (data are not shown here). As for the Yellow group, there was no correlation between baseline and 2nd week aflatoxin biomarkers and food consumption, and thus the data are not presented here. Nevertheless, some positive and significant correlations $(P<0.05)$ were observed between the 4 th week aflatoxin biomarkers and the consumption of macronutrients and dietary fibre. Indeed, the correlation coefficients showed a medium effect size (correlation coefficient $>0 \cdot 3$ ) between the two variables (Table 9).

\section{Discussion}

Aflatoxin exposure in Malaysia is considered to be higher compared with other countries in South East Asia ${ }^{(12,44)}$. To the best of our knowledge, this is the first study conducted in humans investigating the effectiveness of probiotic LcS in reducing the concentrations of serum $\mathrm{AFB}_{1}$-lys and urinary $\mathrm{AFM}_{1}$. The application of probiotics as potential decontaminating agents of aflatoxin is highly promising and may be of immense value in reducing the exposure of this food-borne contaminant in humans. This is evident as a 5 -week intervention study with a mixture of probiotics reduced significantly urinary $\mathrm{AFB}_{1}-N^{7}$-guanine adduct concentration by $55 \%{ }^{(18)}$. This finding was the basis for deciding the present study's duration of 4 weeks. Overall, the intervention did not change both aflatoxin biomarkers' concentrations but the concentrations were reduced in certain subjects who participated in this study. In particular, a significant reduction in the concentrations of serum $\mathrm{AFB}_{1}$-lys was detected and a decreasing trend in the median urinary $\mathrm{AFM}_{1}$ concentration was observed with probiotic drink supplementation among the subjects in the Blue group, but not in the Yellow group. Through these findings, it can be said that the order of probiotic intervention may influence the outcomes obtained here as the efficiency of LcS as an aflatoxin adsorbent was observed in the 1st phase rather than in the 2nd phase of intervention.

This study is one among the few ${ }^{(17,18)}$ that investigated the effect of probiotic bacteria as potential adsorbents of aflatoxin in humans. Furthermore, to make a comparison, for example, the data obtained by El-Nezami et al. ${ }^{(18)}$ can explain a few dissimilarities. First, El-Nezami et $a l^{(18)}$ used a mixture of probiotics, whereas the present study provided subjects with fermented milk drinks containing LcS. Both studies provided almost similar concentrations of bacteria. Hernandez-Mendoza et al. ${ }^{(45)}$ indicated that Lactobacillus strains had different ability to bind $\mathrm{AFB}_{1}$ in vitro. Nevertheless, the effectiveness of LcS treatment was observed in reducing the blood serum concentrations of $\mathrm{AFB}_{1}$ in aflatoxin-induced rats ${ }^{(10,16)}$. As such, differences in the strains of probiotics used could be the possible reason for the observation found here compared with the findings presented by El-Nezami et al. ${ }^{(18)}$.

Second, the biomarker of aflatoxin investigated was different, as El-Nezami et al. ${ }^{(18)}$ measured $\mathrm{AFB}_{1}-N^{\top}$-guanine adduct concentrations, which is a DNA adduct of aflatoxin. The adduct is a short-term biomarker as it is unstable and undergoes rapid de-purination and excretion via urine ${ }^{(46)}$. Indeed, in a pharmacokinetics study of $\mathrm{AFB}_{1}$ involving human volunteers, the excretion 
of $\mathrm{AFB}_{1}$ metabolites via urine occurred rapidly with $>94 \%$ of total urine $\mathrm{AFB}_{1}$ equivalents produced within the first $24 \mathrm{~h}^{(27)}$. However, the concentrations of the $\mathrm{AFB}_{1}-N^{7}$-guanine adduct measured reflected the rate of $\mathrm{AFB}_{1}$-8,9-epoxide formation as well as the competing pathways of $\mathrm{AFB}_{1}-8$,9-epoxide reactions with DNA $v$. glutathione, other macromolecular targets and water ${ }^{(11)}$. As the $\mathrm{AFB}_{1}-N^{7}$-guanine adduct and aflatoxin biomarkers, especially urinary $\mathrm{AFM}_{1}$ concentrations, measured in this study have different metabolic pathways, it can be assumed that differences in the biological activities may contribute to the outcomes found in our study.

Although El-Nezami et $a l^{(18)}$ found that $\mathrm{AFB}_{1}-N^{7}$-guanine adduct was significantly reduced within 3-5 weeks of intervention, it can be postulated that a 4-week intervention study is too short to observe the effects of LCS intervention on the concentrations of serum $\mathrm{AFB}_{1}$-lys and urinary $\mathrm{AFM}_{1}$. It is evident as shown by Wang et al. ${ }^{(23)}$ that a significant reduction of these two aflatoxin biomarkers was only observed after 12 weeks of intervention with NovaSil clay (Engelhard Chemical Corporation). Moreover, a 4-week intervention with NovaSil clay did not change the concentrations of $\mathrm{AFB}_{1}-\mathrm{ALB}$ adduct and urinary $\mathrm{AFM}_{1}$ concentrations ${ }^{(23)}$, which are the same aflatoxin biomarkers investigated in the present study. Considering that probiotic LcS used in this study works in a similar manner as NovaSil clay ${ }^{(23)}$ by binding the aflatoxin molecules, it can be assumed that the 4-week intervention duration may not reveal any significant reduction of aflatoxin biomarkers, preferably serum $\mathrm{AFB}_{1}$-lys and urinary $\mathrm{AFM}_{1}$, but a long intervention period may do so. Indeed, a 25-d intervention with yogurt containing Lactobacillus rhamnosus GR-1 did not find any significant reduction of blood metal levels as compared with the long-term consumption of probiotics ${ }^{(47)}$. The authors also suggested that probiotic consumption does not have a fast-acting effect, but rather acts over the longer term ${ }^{(47)}$.

LcS from the fermented milk has the capacity to survive in the gastrointestinal tract as up to $51 \cdot 2 \%$ ingested bacteria can be found in the ileum ${ }^{(48)}$. Ileum is the last section of the small intestine and the absorption of aflatoxin mostly occurs in the small intestine, where the binding of aflatoxin by bacteria occurs predominantly in the duodenum ${ }^{(49)}$. Assuming that the survival rate of LCS is equivalent to $51 \cdot 2 \%{ }^{(48)}$ and the initial concentration of bacteria is $3 \times 10^{10} \mathrm{CFU} /$ bottle, consumed by the subjects during the intervention, it can be calculated that approximately $1.46 \times 10^{10} \mathrm{CFU} / \mathrm{LCS}$ is still available to prevent the absorption of aflatoxin. The number of bacteria is still sufficient to decrease aflatoxin level as a minimum of $2-5 \times 10^{9} \mathrm{CFU} / \mathrm{ml}$ of bacteria is required to remove $\mathrm{AFB}_{1}$ significantly in vitro ${ }^{(45)}$

Our intervention did not significantly reduce the concentration of aflatoxin biomarkers; however, of the two groups analysed, subjects in the Yellow group did not show any effect towards the probiotic intervention compared with the Blue group. The main route of aflatoxin exposure is through the diets ${ }^{(1,44)}$ and it can be assumed that subjects in the Yellow group were exposed to aflatoxin when they were provided with the probiotic drinks as they had significantly higher frequency of intake of two food items (breads and liquid milk) that are possible sources of aflatoxin (Table 2). Moreover, the intake frequency of some of these foods were also found to be significantly and conversely associated with the concentrations of aflatoxin biomarkers (Table 8). In other words, high intake of foods that are possible sources of aflatoxin corresponds to low concentration of aflatoxin biomarkers during the probiotic intervention period among subjects in the Yellow group. Based on these findings, the application of probiotic LcS theoretically could prevent aflatoxin absorption from the aflatoxin-contaminated foods consumed by the subjects and consequently reduce circular production of serum $\mathrm{AFB}_{1}$-lys and urinary $\mathrm{AFM}_{1}$. However, it was not observed, especially, in the Yellow group with the probiotic intervention. Due to this, we can presume that there may be other factors that can affect the number and/or efficiency of LcS present in the small intestine as aflatoxins are not adsorbed by the bacteria, where the toxin is available for intestinal absorption.

A possible explanation could be due to the dietary intakes of subjects during the intervention. In this study, positive associations were found between urinary $\mathrm{AFM}_{1}$ and fat and protein intakes among subjects in the Yellow group (Table 9) and the intakes of these macronutrients were significantly higher compared with the baseline intakes while they were consuming probiotic drinks (Tables 4 and 5). Nyathi et al. ${ }^{(50)}$ and Hasler et al. ${ }^{(51)}$ showed that high intakes of fat enhanced the activity of detoxification pathways of $\mathrm{AFB}_{1}$ in animal models. A high-fat diet also increased cytochrome $1 \mathrm{~A} 1$ and $2 \mathrm{~B} 1$ activities and reduced the amount of $\mathrm{AFB}_{1}$ available for hepatic macromolecular binding ${ }^{(51)}$. With regard to protein intake, a highprotein diet can stimulate hepatic $\beta$-oxidation process ${ }^{(52)}$, which involves CYP2E1 and CYP4A enzymes, sources of pro-oxidants in liver cell lines ${ }^{(53)}$. Hepatocyte-derived cell lines with high levels of CYP2E1 enzyme produced high levels of $\mathrm{GSH}^{(53)}$ and GSH is important during the detoxification process of aflatoxin $^{(32)}$. Moreover, high intakes of these macronutrients can also affect the secretion of bile acids, as a high-fat diet increases the levels of luminal bile juice in rats ${ }^{(54)}$. Bortolotti et al. ${ }^{(52)}$ found that the total concentration of bile acid increased about $50 \%$ after consumption of high-fat diets. In fact, deoxycholic acid, chenodeoxycholic acid and cholic acid increased significantly in healthy men following a hyperenergetic high-fat, high-protein diet ${ }^{(52)}$. As the survivability of probiotic bacteria in the gastrointestinal tract can be influenced by the concentration of bile juice ${ }^{(55)}$, the ability of LcS to adsorb aflatoxin is affected and becomes limited. As such, there will be more absorption of aflatoxin in the small intestine. Subsequently, the detoxification of $\mathrm{AFB}_{1}$ into $\mathrm{AFM}_{1}$ is favoured due to the high intakes of fat and protein among the subjects. As a result, a high concentration of $\mathrm{AFM}_{1}$ was observed in the Yellow group during the 4 weeks of intervention with the probiotic drinks.

Another scenario that can be explained is the correlation between dietary fibre and urinary $\mathrm{AFM}_{1}$ concentrations (Table 9). Indeed, the intake was significantly higher at the 4 th week of intervention, about $28 \%$ increment compared with the baseline intake during the period of probiotic consumption among subjects in the Yellow group (Table 4). The indirect effect of dietary fibre could be related to the secretion of mucin, the main component of intestinal mucus ${ }^{(56,57)}$. For example, Gratz et al. ${ }^{(58)}$ showed the ability of intestinal mucus to alter the binding of aflatoxin by bacteria in vitro. Mucus pre-incubation 
significantly reduced $\mathrm{AFB}_{1}$ binding by $23.8 \%$ and $61.2 \%$, respectively, for $L$. rhamnosus GG and mixture of $L$. rhamnosus LC-705 and Propionibacterium freudenreichii ssp. shermanii $\mathrm{JS}^{(58)}$. In fact, in vivo animal studies showed the increment of mucin content after the animals were fed a high-dietary fibre diet ${ }^{(59-63)}$. To relate the above explanation with ours, the supposed binding of aflatoxin by LcS might be affected due to the excretion of mucus as a result of high-dietary fibre intake, and thus diminished the ability of LcS to bind aflatoxin. Due to this, there will be more absorption of aflatoxin in the small intestine. As explained previously, aflatoxins are susceptible to the detoxification pathway where $\mathrm{AFM}_{1}$ is produced predominantly. As a result, it was reflected on the concentrations of aflatoxin biomarkers measured, especially urinary $\mathrm{AFM}_{1}$, among subjects in the Yellow group (Table 7).

As explained above, with dietary influence on the detoxification of aflatoxin (the excretion of $\mathrm{AFM}_{1}$ in urine) and the ability of LcS to bind aflatoxin, the concentrations of serum $\mathrm{AFB}_{1}$-lys can be assumed to decrease over the 4 weeks of intervention in the Yellow group. However, the concentration was unchanged and did not show any decreasing trend throughout the 4 weeks of intervention with LcS (Table 6). $\mathrm{AFB}_{1}$-lys is formed through the binding of $\mathrm{AFB}_{1}$-epoxide with protein ALB during the Phase II metabolism ${ }^{(11,31)}$. It is possible that the concentration of $\mathrm{AFB}_{1}$-lys measured during the 4 weeks of intervention reflects aflatoxin exposure during the 2 weeks of wash-out period, as ALB has half-life of about $20 \mathrm{~d}^{(64)}$. Other studies have also indicated that the half-life of $\mathrm{AFB}_{1}$-lys could be between 30 and $60 \mathrm{~d}^{(37)}$. Therefore, the concentration of $\mathrm{AFB}_{1}$-lys measured during the 4 -week intervention could be due to the 'carry over' effect because of a short wash-out period between the phases. It is likely that the subjects were exposed to aflatoxin during the wash-out period, and therefore the concentration of $\mathrm{AFB}_{1}$-lys measured in the 2nd phase among subjects in the Yellow group may reflect exposure during that time.

\section{Limitations and conclusion}

This study found that diets may play a major role on two major aspects - namely, the survival of probiotic LcS in the gastrointestinal tract and the metabolism of aflatoxin. It is very challenging in any intervention study to control the diet of subjects, especially when the duration of the intervention is long. The vastly different diet of the subjects, consumed during the 1 st and 2 nd phase of intervention, may provide an explanation for the observation found in the present study. As humans are exposed to aflatoxins mainly through the diets, it is also very difficult to have a pool of subjects with homogeneous exposure of aflatoxin. Moreover, the short wash-out period could be one of the limitations of the present study. Practically, the duration of the wash-out phase should be based on the half-life of aflatoxin biomarkers measured in the study.

It can be concluded that a 4-week intervention with fermented milk drink containing LcS did not change the concentrations of aflatoxin biomarkers. Nevertheless, the intervention had some effects on subjects who participated in this study. The potential of LcS as an adsorbent of aflatoxin was observed among subjects in the Blue group. Within 2 weeks of intervention, the concentrations of serum $\mathrm{AFB}_{1}$-lys reduced significantly, with a percentage reduction of $17.63 \%$. In fact, the 4 th week concentration of serum $\mathrm{AFB}_{1}$-lys was significantly different between the treatments. Although not significant, a decreasing trend of urinary $\mathrm{AFM}_{1}$ concentration was observed within the last 2 weeks of the intervention. These observations, therefore, suggest that LcS can be used as one of the dietary approaches to prevent human exposure to aflatoxin. Therefore, a longer intervention period is recommended to investigate the effect of continuous consumption of fermented milk drink containing LcS in reducing the concentration of aflatoxin biomarkers. In addition, faecal analysis should also be performed. Besides, the effect of dietary macro and microcomponents on the binding ability of aflatoxin by LcS warrants an in-depth research using in vitro and in vivo models.

\section{Acknowledgements}

This research is a part of S. M. R.'s PhD Thesis submitted to UPM in fulfilment of the requirement for the degree of Doctor of Philosophy. S. M. R. thanks the Ministry of Education, Malaysia, for the scholarship received under MyBrain15 programme (MyPhD) and UPM for the financial aid for research attachment at the University of Georgia, USA. The authors thank the subjects in the study for their contributions.

This research was financially supported by Yakult Honsha Co. Ltd and managed by UPM Holdings Sdn. Bhd. (project no. 278).

S. M. R. contributed to the study design, analysis, data interpretation and writing of the manuscript. M. S. A. M., Z. A. and R. J. contributed to the experimental design, data analysis and interpretation and provided constructive comments and advices in preparing the manuscript. J.-S. W. and M.-S. K. aided in the analysis of $\mathrm{AFB}_{1}$-lys at the University of Georgia, USA. N. 'A. A. R. analysed the 2-d food record. E. N. N. helped in preparing and reviewing the manuscript.

None of the authors has any conflicts of interest.

\section{References}

1. Sabran MR, Jamaluddin R \& Abdul Mutalib MS (2012) Screening of aflatoxin $\mathrm{M}_{1}$, a metabolite of aflatoxin $\mathrm{B}_{1}$ in human urine samples in Malaysia: a preliminary study. Food Control 28, 55-58.

2. Reddy KRN, Farhana NI \& Salleh B (2011) Occurrence of Aspergillus spp. and aflatoxin $\mathrm{B}_{1}$ in Malaysian foods used for human consumption. J Food Sci 76, T99-T104.

3. International Agency for Research on Cancer (IARC), World Health Organization (2002) Aflatoxin: Some Traditional Herbal Medicines, Some Mycotoxins, Naphthalene and Styrene. IARC Monograph on the Evaluation of Carcinogenic Risk to Humans, vol. 82]. Lyon: IARC Press.

4. Strosnider H, Azziz-Baumgartner E, Banziger M, et al. (2006) Workgroup report: public health strategies for reducing aflatoxin exposure in developing countries. Environ Health Perspect 114, 1898-1903.

5. Jolly CM, Bayard B, Awuah RT, et al. (2009) Examining the structure of awareness and perceptions of groundnuts aflatoxin among Ghanaian health and agricultural professionals and its influence on their actions. J Socio Econ 38, 280-287. 
6. Ilesanmi FF \& Ilesanmi OS (2011) Knowledge of aflatoxin contamination in groundnut and risk of its ingestion among health workers in Ibadan, Nigeria. Asian Pac J Trop Biomed 1, 493-495.

7. Mohd Redzwan S, Rosita J, Mohd Sokhini AM, et al. (2012) Socio-demographic and socio-economic determinants of adults' knowledge on fungal and aflatoxin contamination in the diets. Asian Pac J Trop Biomed 2, S1835-S1841.

8. Leong Y-H, Rosma A, Latiff AA, et al. (2012) Associations of serum aflatoxin $\mathrm{B}_{1}$-lysine adduct level with socio-demographic factors and aflatoxin intake from nuts and related nuts products in Malaysia. Int J Hyg Environ Health 215, 368-372.

9. Lye MS, Ghazali AA, Mohan J, et al. (1995) An outbreak of acute hepatic encephalopathy due to severe aflatoxicosis in Malaysia. Am J Trop Med Hyg 53, 68-72.

10. Lewis L, Onsongo M, Njapau H, et al. (2005) Aflatoxin contamination of commercial maize products during an outbreak of acute aflatoxicosis in Eastern and Central Kenya. Environ Health Perspect 113, 1763-1767.

11. Kensler TW, Roebuck BD, Wogan GN, et al. (2011) Aflatoxin: a 50-year odyssey of mechanistic and translational toxicology. Toxicol Sci 120, S28-S48.

12. Liu Y \& Wu F (2010) Global burden of aflatoxin-induced hepatocellular carcinoma: a risk assessment. Environ Health Perspect 118, 818-824.

13. El-Nezami H, Kankaanpaa P, Salminen S, et al. (1998) Ability of dairy strains of lactic acid bacteria to bind a common food carcinogen, aflatoxin B1. Food Chem Toxicol 36, 321-326.

14. Hernandez-Mendoza A, Guzman-De-Pena D, GonzalezCordova AF, et al. (2010) In vivo assessment of the potential protective effect of Lactobacillus casei Shirota against aflatoxin $\mathrm{B}_{1}$. Dairy Sci Technol 90, 729-740.

15. Kabak B \& Ozbey F (2012) Assessment of the bioaccessibility of aflatoxins from various food matrices using an in vitro digestion model, and the efficacy of probiotic bacteria in reducing bioaccessibility. J Food Compost Anal 27, 21-31.

16. Nikbakht Nasrabadi E, Jamaluddin R, Abdul Mutalib MS, et al. (2013) Reduction of aflatoxin level in aflatoxin-induced rats by the activity of probiotic Lactobacillus casei strain Shirota. J Appl Microbiol 114, 1507-1515.

17. El-Nezami H, Mykkänen H, Kankaanpää P, et al. (2000) Ability of a mixture of Lactobacillus and Propionibacterium to influence the faecal aflatoxin content in healthy Egyptian volunteers: a pilot clinical study. Biosci Microflora 19, 41-45.

18. El-Nezami HS, Polychronaki NN, Ma J, et al. (2006) Probiotic supplementation reduces a biomarker for increased risk of liver cancer in young men from Southern China. Am J Clin Nutr 83, 1199-1203.

19. Romero AC, Ferreira TRB, Dias CTS, et al. (2010) Occurrence of $\mathrm{AFM}_{1}$ in urine samples of a Brazilian population and association with food consumption. Food Control 21, 554-558.

20. Mohd Redzwan S, Rosita J, Mohd Sokhini AM, et al. (2012) Association between aflatoxin $\mathrm{M}_{1}$ excreted in human urine samples with the consumption of milk and dairy products. Bull Environ Contam Toxicol 89, 1115-1119.

21. Shuaib FM, Jolly PE, Ehiri JE, et al. (2011) Association between birth outcomes and aflatoxin $\mathrm{B}_{1}$ biomarker blood levels in pregnant women in Kumasi, Ghana. Trop Med Int Health 15, 160-167.

22. Polychronaki N, Wild CP, Mykkänen H, et al. (2008) Urinary biomarkers of aflatoxin exposure in young children from Egypt and Guinea. Food Chem Toxicol 46, 519-526.

23. Wang P, Afriyie-Gyawu E, Tang Y, et al. (2008) NovaSil clay intervention in Ghanaians at high risk for aflatoxicosis: II. Reduction in biomarkers of aflatoxin exposure in blood and urine. Food Addit Contam Part A Chem Anal Control Expo Risk Assess 25, 622-634.

24. Turner PC, Sylla A, Gong YY, et al. (2005) Reduction in exposure to carcinogenic aflatoxin by postharvest intervention measures in West Africa: a community-based intervention study. Lancet 365, 1950-1956.

25. Tang L, Tang M, Xu L, et al. (2008) Modulation of aflatoxin biomarkers in human blood and urine by green tea polyphenols intervention. Carcinogenesis 29, 411-417.

26. Hsieh DPH \& Wong JJ (1994) Pharmacokinetics and excretion of aflatoxins. In The Toxicology of Aflatoxins: Human Health, Veterinary, and Agricultural Significance, pp. 73-88 [DL Eaton and JD Groopman, editors]. San Diego, CA: Academic Press Inc.

27. Jubert C, Mata J, Bench G, et al. (2009) Effects of chlorophyll and chlorophyllin on low-dose aflatoxin $\mathrm{B}_{1}$ pharmacokinetics in human volunteers. Cancer Prev Res 2, 1015-1022.

28. Coulombe RA Jr \& Sharma RP (1985) Clearance and excretion of intratracheal and orally administered aflatoxin B1 in the rat. Food Chem Toxicol 23, 827-830.

29. Wilson R, Ziprin R, Ragsdale S, et al. (1985) Uptake and vascular transport of ingested aflatoxin. Toxicol Lett 29, 169-176.

30. Kumagi S (1989) Intestinal absorption and excretion of aflatoxin in rats. Toxicol Appl Pharmacol 97, 88-97.

31. Wogan GN (1969) Metabolism and biochemical effects of aflatoxin. In Aflatoxin - Scientific Background, Control and Implications, pp. 151-186 [LA Goldblatt, editor]. New York: Academic Press.

32. Wang JS, Shen X, He X, et al. (1999) Protective alteration in phase 1 and phase 2 metabolism of aflatoxin $\mathrm{B}_{1}$ by oltipraz in residents of Qidong, People's Republic of China. J Natl Cancer Inst 91, 347-354.

33. Mykkänen H, Zhu H, Salminen E, et al. (2005) Fecal and urinary excretion of aflatoxin B1 metabolites (AFQ1, AFM1 and AFB- $N^{7}$-guanine) in young Chinese males. Int $J$ Cancer 115, 879-884.

34. Partanen HA, El-Nezami HS, Leppänen JM, et al. (2010) Aflatoxin B1 transfer and metabolism in human placenta. Toxicol Sci 113, 216-225.

35. Zhu JQ, Zhang LS, Hu X, et al. (1987) Correlation of dietary aflatoxin B1 levels with excretion of aflatoxin M1 in human urine. Cancer Res 47, 1848-1852.

36. Egmond HPV (1994) Aflatoxins in milk. In The Toxicology of Aflatoxins: Human Health, Veterinary, and Agricultural Significance, pp. 365-380 [DL Eaton and JD Groopman, editors]. San Diego, CA: Academic Press Inc.

37. Williams JH, Phillips TD, Jolly PE, et al. (2004) Human aflatoxicosis in developing countries: a review of toxicology, exposure, potential health consequences, and interventions. Am J Clin Nutr 80, 1106-1122.

38. Mohd Redzwan S, Rosita J, Mohd Sokhini AM, et al. (2014) Detection of serum $\mathrm{AFB}_{1}$-lysine adduct in Malaysia and its association with liver and kidney functions. Int J Hyg Environ Health 217, 443-451.

39. Cupid BC, Lightfoot TJ, Russell D, et al. (2004) The formation of $\mathrm{AFB}_{1}$-macromolecular adducts in rats and humans at dietary levels of exposure. Food Chem Toxicol 42, 559-569.

40. Rosnow RI \& Rosenthal R (1996) Computing contrasts, effect sizes and counternulls on other people's published data: general procedures for research consumers. Psycho Methods 1, 331-340.

41. Julios SA (2004) Tutorial in biostatistics. Sample size for clinical trials with normal data. Stat Med 23, 1921-1986.

42. Tee ES, Mohd Ismail N, Mohd Nasir A, et al. (1997) Nutrient Composition of Malaysian Foods, 4th ed. Kuala Lumpur: Institute for Medical Research. 
43. Mohd Redzwan S, Jamaluddin R, Mohd Sokhini AM, et al. (2015) Ultra-high performance liquid chromatographic determination of aflatoxin $\mathrm{M}_{1}$ in urine. World Mycotoxin J $\mathbf{8}$, 405-413.

44. Mohd-Redzwan S, Jamaluddin R, Abd-Mutalib MS, et al. (2013) A mini review on aflatoxin exposure in Malaysia: past, present and future. Front Microbiol 4, 1-8.

45. Hernandez-Mendoza A, Garcia HS \& Steele JL (2009) Screening of Lactobacillus casei strains for their ability to bind aflatoxin $\mathrm{B}_{1}$. Food Chem Toxicol 47, 1064-1068.

46. Egner PA, Groopman JD, Wang J-S, et al. (2006) Quantification of aflatoxin- $\mathrm{B}_{1}-N^{7}$-guanine in human urine by high-performance liquid chromatography and isotope dilution tandem mass spectrometry. Chem Res Toxicol 19, 1191-1195.

47. Bisanz JE, Enos MK, Mwanga JR, et al. (2014) Randomized open-label pilot study on the influence of probiotics and the gut microbiome on toxic metal levels in Tanzanian pregnant women and school children. MBio 5, 1-7.

48. Oozeer R, Leplingard A, Mater DD, et al. (2006) Survival of Lactobacillus casei in the human digestive tract after consumption of fermented milk drink. Appl Environ Microbiol 72, 5615-5617.

49. Hernandez-Mendoza A, Rivas-Jimenez L \& Garcia HS (2011) Assessment of aflatoxin $\mathrm{B}_{1}$ binding to Lactobacillus reuteri by microscopy and fluorescence techniques. Food Biotechnol 25, 140-150.

50. Nyathi CB, Dube N, Hasler JA, et al. (1993) The effect of diet on aflatoxin B1 binding to hepatic macromolecules in rats. Res Commun Chem Pathol Pharmacol 82, 199-207.

51. Hasler JA, Dube N, Nyathi CB, et al. (1994) The influence of dietary fat on hepatic bioactivation of aflatoxin B1 in rats. Res Commun Chem Pathol Pharmacol 83, 279-287.

52. Bortolotti M, Kreis R, Debard C, et al. (2009) High protein intake reduces intrahepatocellular lipid deposition in humans. Am J Clin Nutr 90, 1002-1010.

53. Robertson G, Leclercq I \& Farrell GC (2001) Nonalcoholic steatosis and steatohepatitis. II. Cytochrome P-450 enzymes and oxidative stress. Am J Physiol Gastrointest Liver Physiol 281, G1135-G1139.

54. Suzuki T \& Hara H (2010) Dietary fat and bile juice, but not obesity, are responsible for the increase small intestinal permeability induced through the suppression of tight junction protein expression in LETO and OLETF rats. Nutr Metab (Lond) 12, 7-19.

55. Sahadeva RPK, Leong SF, Chua KH, et al. (2011) Survival of commercial probiotic strains to $\mathrm{pH}$ and bile. Int Food Res J 18, $1515-1522$

56. Montagne I, Peil C \& Lallès JP (2004) Effect of diet on mucin kinetics and composition: nutrition and health implications. Nutr Rev 62, 105-114.

57. Johansson ME, Ambort D, Pelaseyed T, et al. (2011) Composition and functional role of the mucus layers in the intestine. Cell Mol Life Sci 68, 3635-3641.

58. Gratz S, Mykkänen H, Ouwehand C, et al. (2004) Intestinal mucus alters the ability of probiotic bacteria to bind aflatoxin $\mathrm{B}_{1}$ in vitro. Appl Environ Microbiol 70, 6306-6308.

59. Fuller MF \& Cadenhead A (1991) Effect of the amount and composition of the diet on galactosamine flow from the small intestine. In Proceedings of the Vth International Symposium on Digestive Physiology in Pigs, 54, pp. 330-333 [MWA Verstegen, J Huisman and LA Den Hartog, editors]. Wageningen: EAAP Publication.

60. Mariscal-Landin G, Sève B, Collèaux Y, et al. (1995) Endogenous amino nitrogen collected from pigs with end-to-end ileorectal anastomosis is affected by the method of estimation and altered by dietary fibre. J Nutr 125, 136-146.

61. Leterme P, Froidmont E, Rossi F, et al. (1998) The high water-holding capacity of pea inner fibre affects the ileal flow of endogenous amino acids in pigs. J Agric Food Chem $\mathbf{4 6}$, $1927-1934$

62. Lien KA, Saucer WC \& He JM (2001) Dietary influence on the secretion into and degradation of mucin in the digestive tract of monogastric animals and humans. J Anim Feed Sci 10, 223-245.

63. Morita T, Tanabe H, Ito H, et al. (2008) Long-term ingestion of insoluble dietary fiber increases luminal mucin content, but has no effect on nutrient absorption in rats. Biosci Biotechnol Biochem 72, 767-772.

64. Christopher PW, Jiang Y-Z, Sabbioni G, et al. (1990) Evaluation of methods for quantitation of aflatoxin-albumin adducts and their application to human exposure assessment. Cancer Res 50, 245-251. 